\title{
El retorno a la pintura Entrevista a Julio Paz
}

\author{
Return to Painting \\ Dialogue with Julio Paz
}

María de los Ángeles de Rueda

mariaderueda@gmail.com

Instituto de Historia del Arte

Argentino y Americano

Facultad de Bellas Artes

Universidad Nacional de La Plata

Argentina

Recibido: $11 / 9 / 2017$

Aceptado: 20/2/2018

\section{Resumen}

Para contribuir con las historiografías futuras transcribo una entrevista que realicé en enero de 1994 al artista Julio Paz, quien se encontraba en Buenos Aires visitando a su hermana, la grabadora Hilda Paz. El artista, reconocido en el exterior, había sentido su carrera truncada en el país por la censura y por la persecución de la dictadura, a pesar de haber obtenido el gran premio de honor. Y con la humildad de un grande se alegró de que me interesara por su obra, que formó parte de mi objeto de tesis de posgrado. Pero la entrevista nunca salió publicada en el boletín del instituto por haberse suspendido su edición al cabo de diez años.

\section{Palabras clave}

Pintura; exilio; narración

\begin{abstract}
To contribute to future historiographies I transcribe an interview that I conducted in January 1994 to the artist Julio Paz, who at that moment was visiting his sister, the graver Hilda Paz. The artist, recognized abroad, felt that his career had been truncated in the country by the censorship and persecution of the dictatorship, despite having obtained the grand prize of honor. And with the humility of a great, he was glad that I was interested in his work, which was part of my postgraduate thesis. But the interview was never published in the institute's bulletin because its edition was suspended after ten years.
\end{abstract}

\section{Keywords}

Painting; exile; narration 
Julio Paz fue un pintor y grabador nacido en Buenos Aires en 1939. En 1971 obtuvo el Gran Premio de Honor de Grabado del Salón Nacional. Después de su formación en la Escuela de Bellas Artes Carlos Morel de Quilmes y en la Escuela Superior de Bellas Artes Ernesto de la Cárcova, enseñó dibujo y grabado hasta 1976. En el marco del terrorismo de Estado fue amenazado de muerte y tuvo que exiliarse en Milán, donde vivió hasta sus últimos días. Unos meses antes del exilio expuso en Buenos Aires la primera parte de la serie La Condición Humana, aguafuertes satíricos, grotescos, inspirados en la realidad política y social de la Argentina, en el cruce de imágenes populares y masivas. A partir de 1986 alternó sus actividades entre Milán, Berlín y Buenos Aires. Ciclos importantes de su obra gráfica y pictórica fueron dedicados a temas tales como La verdadera entrada triunfal de Vincent en Bernal, y Días y noches con Van Gogh. En 1989 comenzó Bernal/Berlín, dedicado a las dos ciudades efectivamente relacionadas con su vida y desde 1996 trabajó en la serie sobre Calas y erotismo. Recibió prestigiosos premios internacionales de grabado y de pintura en muchos países, entre ellos Argentina, Alemania, Polonia, Japón, Estados Unidos e Italia. En 2008, por invitación de la ciudad de Milán y del Consulado Argentino, se presentó una antología de sus obras titulada $L a$ mano que, en el Palacio Real de Milán. Murió en esa ciudad el 5 de febrero de 2010. El Centro de Investigación Julio Paz alberga su trabajo.

Dos años antes de esta entrevista, participé del equipo de investigación y curaduría de la muestra El grabado social y político en la Argentina del siglo XX, realizada en el Museo de Arte Moderno de Ciudad Autónoma de Buenos Aires y en el Museo Provincial de Bellas Artes de La Plata, con la coordinación de Raul Santana y de Alfredo Benavidez Bedoya. Entre los artistas que trabajé estuvo Julio Paz con sus aguafuertes. El encuentro y el diálogo se desarrollaron en enero de 1994 en Bernal, en la casa familiar del artista. Mi propósito en ese tiempo de joven investigadora era reunir fuentes testimoniales de artistas argentinos contemporáneos que trabajaban en clave grotesca, satírica, paródica, y de los cuales había muy poca información y estudios históricos-críticos; Paz me interesaba no solo por su condición de exilado político sino por su matriz figurativa crítica. La entrevista trascurrió en una jornada muy amena y esclarecedora. Él, desde el exterior, veía más matizadas algunas asperezas y contradicciones de la historiografía canónica y celebró mis búsquedas de visibilizar artistas excluidos, olvidados o silenciados. El material recogido en la entrevista sirvió para apuntalar mis hipótesis y mis intuiciones en la tesis de maestría y en algunas publicaciones sobre el tema. Sin embargo, la entrevista como tal fue enviada para su publicación a un número de Boletín de Arte del Instituto de Historia del Arte Argentino y Americano de la Facultad de Bellas Artes que nunca salió. Trece años más tarde encontré una copia y decidí volver a escribirla para compartirla en esta edición. 
La pintura se suspendió con el viaje de 1976 y el inicio del exilio me obligó a estar en otro país con problemas de idioma y de trabajo, a reducir mucho la actividad plástica durante un año. No obstante, pude dibujar en varias técnicas, pastel y acrílicos, y con esas series hice dos exposiciones en Milán.

Al principio vivía en una pensión. Luego conseguí una casa donde instalé un estudio para hacer grabado. Hasta el año 1980 trabajé en el estudio del litógrafo Giorgio Upiglio; más tarde compré una prensa. Para subsistir trabajaba como diseñador de Olivetti y con ese trabajo pude volver a la pintura, actividad que siempre estuvo presente (la serie de Los inventos 1972-73, el retrato del general Lavater). La representación siempre se centró en la historia reinventada. La realidad fue una constante, la evidencia de que el contexto te define y vos lo definís. No hice obra manifestando la represión. Algo tan horroroso no puede ser estético. Subliminalmente, se puede ser feroz en la denuncia. Una elipsis. Siempre estuvieron presentes la realidad, los mitos, los ídolos, los amores, los lugares.

\section{¿Lo narrativo es decisivo en tu obra?}

Mucha gente asoció mi obra al realismo socialista y no tiene ninguna relación. Por una parte, la perspectiva de algunos personajes, como Carlos Alonso, Antonio Berni, Aída Carballo, José Guadalupe Posada, me ha enseñado a ver. Por otra parte, soy admirador ferviente de William Hogarth, a quien aprendí a observar. A Otto Dix no se me ocurrió copiarlo. Primero aprendí con Durero, luego con Rembrandt y con Pietro Longhi. Me hubiera gustado tener, alguna vez, una pincelada como la de Goya o hacer una mano como Carlos Alonso. Son pequeños sueños de admiración por los grandes.

¿Cómo recibe el público internacional las series con historias personales o pertenecientes a un contexto regional, incluso, familiar? ¿Cómo crees que se conectan los espectadores?

(Paz recordó el Gran Premio en la Primera Muestra Internacional de Grabado, en 1985, en el Museo Metropolitano de Tokio, con la obra Los padres del artista). Los japoneses, por ejemplo, tienen capacidad de reflexión, de compresión temática. Carecen de arrogancia frente al problema estético. Se despojan de la soberbia en la lectura de la obra de otra persona.

En Italia existe cierto paternalismo hacia el arte latinoamericano, frenado hace un tiempo por el éxito de Frida Kahlo. Por ejemplo, los excepcionales dibujos de Diego Rivera podrían haber tenido un espacio mayor. Se considera mucho lo latinoamericano como subproducto. Por mi parte, creo que existe una cultura latinoamericana a pesar de las contradicciones. Se ve claramente en la literatura que ha creado un foco de choque: Onetti, Macedonio, 
Gelman. Es un gran esfuerzo imponer a un grupo de artistas sin el prejuicio de que primero hayan pasado por lo europeo.

¿Crees que el humor, la sátira, la parodia, tienen que ver con algún rasgo de nuestra identidad?

Sin duda, y la ironía. Hablemos de autoironía. No hay solemnidad en nuestros artistas. Títulos de obras que se permitirían, Antonio Seguí y algún otro artista, yo no lo he encontrado en el arte europeo, salvo en Holanda o en Alemania. El peso de la ironía y de la no solemnidad lo veo tan difundido entre los argentinos como en los mejicanos y en algunos chilenos. Ya Picasso y Bacon demostraron que no hay que ser solemnes. Es muy difícil cambiar el contexto en el que se ha vivido, no se puede renunciar a ello.

¿Podés hacer un balance de los años setenta en las artes visuales?

Siempre trabajé de manera bastante autónoma, pero en esos años hicimos cosas con Juan Carlos Romero y con Hilda Paz con la idea de difundir el grabado; participamos por medio de GRABAS, un grupo con el que realizábamos eventos en la calle. Frecuentaba a artistas como Audivert y Zelaya. También realicé muestras individuales en Santa Fe, Tucumán y Buenos Aires, en la Art Gallery donde expuse La condición humana, pocos meses antes de tener que dejar la Argentina por las amenazas de la Triple A y los militares. En esa galería habían expuesto Maccio, Seguí, Alonso, Paparella. Había fuerza, interés, garra.

\section{¿Cómo concebís las citas y las referencias en tu obra?}

En general, como un homenaje. Por ejemplo, la pintura y el grabado en torno a Cándido López fueron homenajes, no por la guerra en la que participó sino por el coraje y la pasión por la pintura y la verdad. Él había inventado una buena perspectiva para las tomas del paisaje. Recuerdo haber visto su obra en una muestra itinerante en Roma. A veces, conseguir un modelo no es fácil, entonces es bueno conseguir fotografías que trasciendan la mera expresión y uno luego agrega vida al personaje. Soy un realista, tengo una visión ética del mundo con un poco de poesía [Figura 1]. 

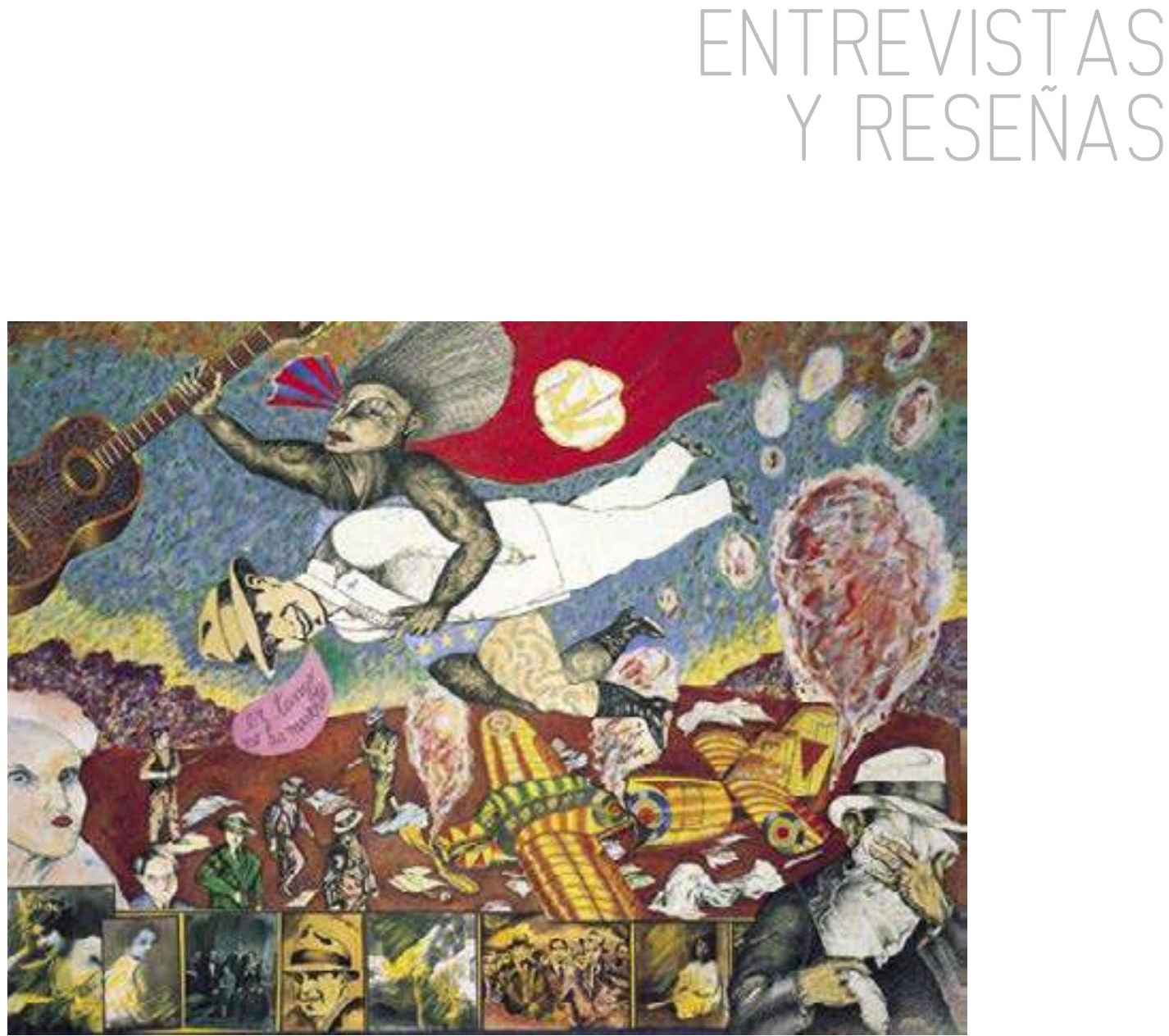

Figura 1. Hilda, la Mujer Maravilla, salva a Gardel del desastre de Medellín (1982), Julio Paz. Acrílico, 150 × $200 \mathrm{~cm}$ 